\title{
A case report of valve-sparing aortic root replacement in a patient with full metal jacket aorta
}

\author{
Masahide Kawatou, Kenji Minatoya, Kazuhiro Yamazaki, Hideo Kanemitsu, Kazuhisa Sakamoto, \\ Jiro Sakai \\ Department of Cardiovascular Surgery, Kyoto University Graduate School of Medicine, Kyoto, Japan \\ Correspondence to: Dr. Kenji Minatoya, MD, PhD. Department of Cardiovascular Surgery, Kyoto University Graduate School of Medicine, 54 \\ Kawahara-cho, Shogoin, Sakyo-ku, Kyoto 606-8507, Japan. Email: minatoya@kuhp.kyoto-u.ac.jp.
}

\begin{abstract}
With the spread of thoracic endovascular aortic repair (TEVAR), open conversions in the remote period have increased. We present a case of a 61-year-old male patient who had aortic root dilatation with aortic regurgitation and previous ascending aortic replacement for acute aortic dissection and zone 0 TEVAR with the chimney stent graft into the brachiocephalic artery with a bypass between bilateral carotid arteries. The patient was successfully treated with valve-sparing aortic root replacement and arch replacement. The chimney stent graft was entirely removed, and the proximal part of the primary aortic stent graft was also cut out. The distal side of the aortic arch was reconstructed using Vascutek Siena ${ }^{\mathrm{TM}}$ Collared Branched Graft (Terumo Vascutek, Tokyo, Japan). The cause of aortic valve insufficiency was not only root dilatation but also rupture of fenestration in the left coronary cusp. The aortic root was reconstructed using the reimplantation technique with Gelweave ${ }^{\mathrm{TM}}$ Valsalva Graft (Terumo Vascutek, Tokyo, Japan), and the left coronary cusp was repaired using the free margin resuspension technique. The postoperative course was uneventful, and at a one-year follow-up, the patient was free of complications. Because reoperation of post-TEVAR could be difficult due to unusual vascular structures, careful application of TEVAR for the aortic arch is required.
\end{abstract}

Keywords: Valve-sparing aortic root replacement; full metal jacket aorta; case report

Received: 04 May 2020; Accepted: 25 November 2020; Published: 20 July 2022.

doi: 10.21037 /jovs-20-108

View this article at: http://dx.doi.org/10.21037/jovs-20-108

\section{Introduction}

After Dake et al. first reported the clinical feasibility of endovascular repair for descending thoracic aortic aneurysms in 1994 (1), thoracic endovascular aneurysm repair (TEVAR) has become popular because of its less invasiveness and low perioperative mortality $(2,3)$. Furthermore, the variety of modifications to the endovascular technique such as branched stent graft, fenestrated stent graft, debranching technique, and chimney technique have been applied to overcome anatomical limitations with aortic arch (4-7).

However, with the spread of TEVAR, open conversions in the remote period have increased. Coselli et al. reported that the rates of open repairs after TEVAR have ranged from $0.4 \%$ to $7.9 \%$. Major reasons for open repair included endoleak (especially type I), aortic fistula, endograft infection, device collapse or migration, and continued expansion of the aneurysm sac (8). In a study by Roselli et al. of 50 patients who underwent open repair after TEVAR, hospital mortality occurred in $3(6 \%)$ patients. Survival was $67 \%$ at a median follow-up of 2.9 years (9). Although these results are acceptable, the open repair after TEVAR often has difficulties due to the unusual vascular structure. We reported valve-sparing aortic root replacement and arch replacement in a patient with full metal jacket aorta. We present the following case in accordance with the CARE reporting checklist (available at https://jovs.amegroups.com/article/ view/10.21037/jovs-20-108/rc).

\section{Case presentation}

A 61-year-old male patient was referred to our hospital 
Table 1 Patient's medical history

\begin{tabular}{llll}
\hline Age (years) & Disease status & Treatment & Outcome \\
\hline 57 & Acute type A aortic dissection & Ascending aortic replacement & He was saved and recovered \\
58 & $\begin{array}{l}\text { Narrowing true lumen of the } \\
\text { distal arch related to chronic type A } \\
\text { aortic dissection }\end{array}$ & $\begin{array}{l}\text { Zone 0 TEVAR with the chimney stent graft } \\
\text { into the brachiocephalic artery and bypass } \\
\text { between right and left carotid arteries }\end{array}$ & The true lumen expanded \\
& Pleural effusion & Starting diuretics medication & The pleural effusion decreased \\
60 & Glomerulonephritis & Starting steroids medication & The renal function was maintained \\
& Aortic valve regurgitation and & Valve-sparing aortic root replacement and & The aortic root and arch were successfully \\
61 & Endoleaks in the false lumen of the & arch replacement & reconstructed
\end{tabular}

TEVAR, thoracic endovascular aortic repair.

because of aortic root dilatation with aortic valve regurgitation. At age 57, he had ascending aortic replacement for acute type A aortic dissection in Thailand. At age 58, he had zone 0 TEVAR with the chimney stent graft into the brachiocepalic artery and had a bypass between right and left carotid arteries for narrowing true lumen of the distal arch related to chronic type A aortic dissection. At age 60, he was treated by diuretics because of pleural effusion, and he was treated by steroid because of glomerulonephritis. After that, aortic valve regurgitation has been gradually deteriorated (Table 1).

In the preoperative examination, contrast-enhanced CT showed a primary stent graft inserted from the ascending aorta to the Th12 level of descending aorta, and chimney stent graft was inserted from the brachiocephalic artery into ascending aorta (Figure 1A). Endoleaks were detected in the false lumen of the aortic arch and the descending aorta (Figure $1 B$ ). In the measurement of the aortic root, the diameter of the $\mathrm{AV}$ annulus was $26.0 \mathrm{~mm}$, the diameter of the Valsalva was $40.6 \mathrm{~mm}$, and the diameter of the sinotubular junction (STJ) was $37.8 \mathrm{~mm}$. Cardiac ultrasonography showed that the grade of aortic valve regurgitation was moderate to severe (Figure 1C), left ventricular end-diastolic diameter (LVDd) was $56.3 \mathrm{~mm}$, left ventricular end-systolic diameter (LVDs) was $31.8 \mathrm{~mm}$, and LVEF was $74.1 \%$. We planned valve-sparing aortic root replacement and arch replacement.

Surgery was performed through a median resternotomy (Video 1). A cardiopulmonary bypass was established through arterial cannulation to the bilateral axillary arteries (NextGen 10 Fr: Medtronic, Santa Rosa, CA, USA) and femoral artery (TOYOBO 20 Fr: TOYOBO CO, Osaka, Japan), and venous cannulation to the right atrium to
IVC (DLP 31 Fr: Medtronic, Santa Rosa, CA, USA) and SVC (V cannula 30 Fr: Medtronic, Santa Rosa, CA, USA) (Figure 2A). Under deep hypothermic circulatory arrest (minimum pharyngeal temperature: $17.0^{\circ} \mathrm{C}$ ), the aortic arch was dissected, and the chimney stent graft (Endurant: Medtronic, Santa Rosa, CA, USA) inserted to the brachiocephalic artery was entirely removed (Figure $2 B$ ). A 15 Fr cannula (SUMITOMO BAKELITE CO, Tokyo, Japan) was inserted into the right carotid artery, and the selective cerebral perfusion was established. The proximal part of the primary stent graft (Valiant: Medtronic, Santa Rosa, CA, USA) inserted just above the STJ was cut off and partially removed. The incision of the aorta was advanced toward the aortic arch, and the left carotid artery was identified without blood backflow. There was the junction of the two stent grafts in the distal arch, with the distal stent graft inserted into the proximal stent graft. The distal side of the aortic arch was reconstructed by using Vascutek Siena ${ }^{\mathrm{TM}}$ Collared Branched Graft $24 \mathrm{~mm} .5 \mathrm{~cm}$ elephant trunk was inserted into the descending aorta, and the stump of cutting stent graft and the aortic wall were anastomosed to the trimmed collar of the new artificial graft (Figure 2C,2D). In the appearance of the aortic root, the cause of aortic valve insufficiency was not only root dilatation but also rupture of fenestration in the left coronary cusp (Figure 2E). The aortic root was reconstructed using reimplantation technique with and Gelweave ${ }^{\mathrm{TM}}$ Valsalva $26 \mathrm{~mm}$, and the left coronary cusp was repaired with Gore-Tex sutures (W. L. Gore \& Associates, Flagstaff, AZ, USA) (Figure 2F). The right carotid artery and the right subclavian artery were reconstructed (Figure $2 G$ ). Reconstruction of the left subclavian artery was abandoned because of fragile vascular property. Operation time was 17 hours 19 minutes, 


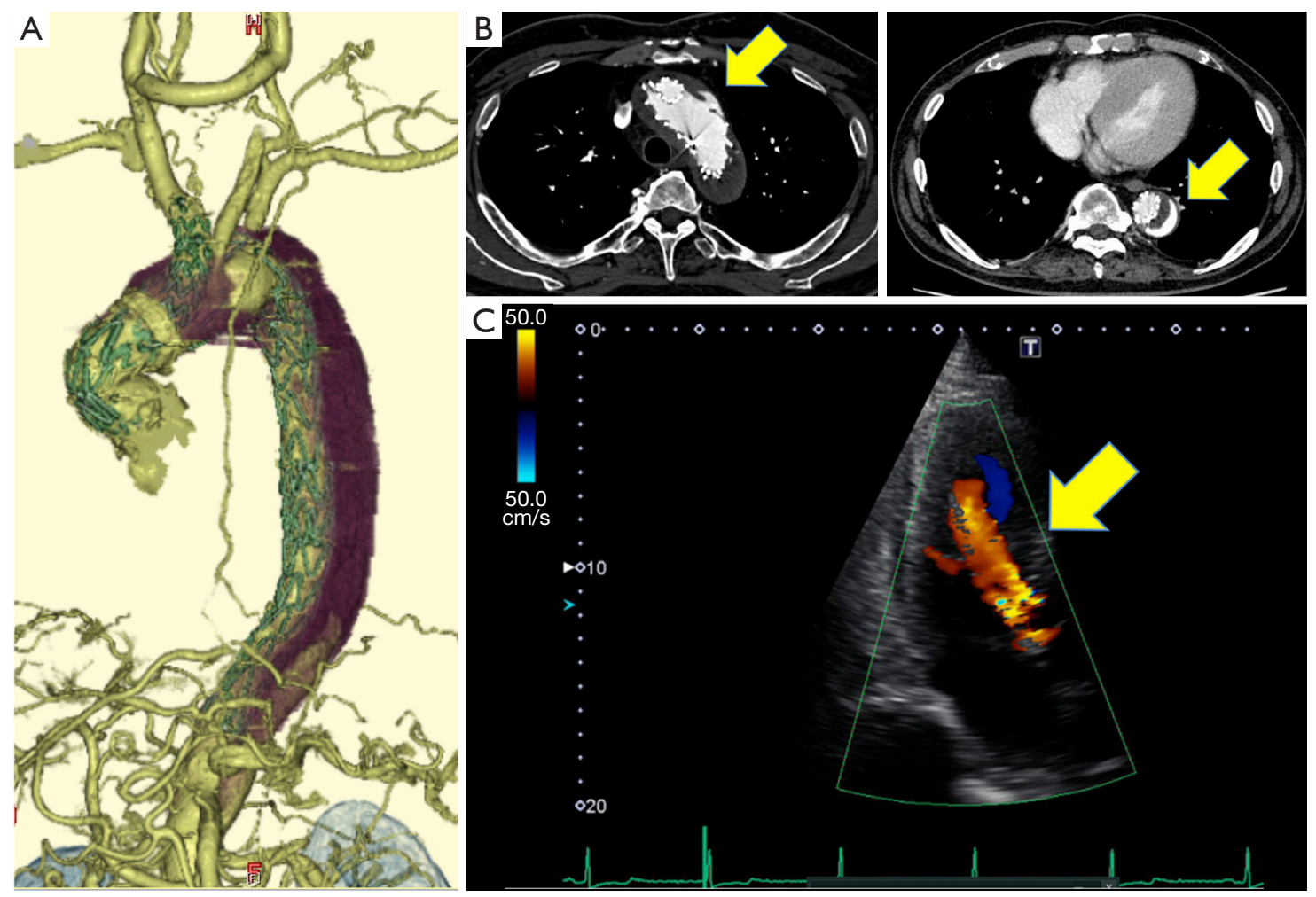

Figure 1 Pre-operative finding (A) 3D-CT image. (B) Serial CT images with endoleaks (arrow) in false limen. (C) Ultrasonography image of aortic valve regurgitation (arrow).

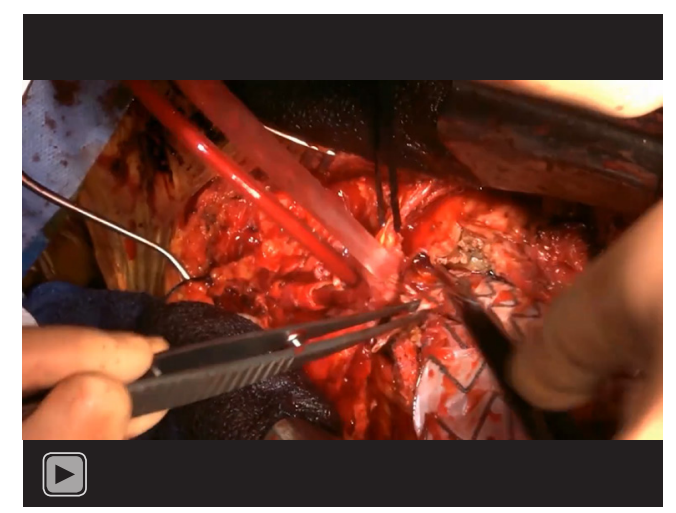

Video 1 A case report of valve-sparing aortic root replacement in a patient with full metal jacket aorta.

circulation arrest time (lower body) was 92 minutes, CPB time was 554 minutes, selective cerebral perfusion time was 441 minutes, and aorta clamp time was 286 minutes.

The postoperative course was uneventful. In the postoperative examination, contrast-enhanced CT showed false lumen thrombosis from the distal arch to descending aorta (Figure $3 A, 3 B$ ). In the measurement of the base of the aorta, the diameter of the AV annulus was $25.2 \mathrm{~mm}$, the diameter of the Valsalva was $28.6 \mathrm{~mm}$, and the diameter of the STJ was $27.4 \mathrm{~mm}$. Cardiac ultrasonography showed that the grade of aortic valve regurgitation was trivial (Figure 3C), LVDd was $43.0 \mathrm{~mm}$, LVDs was $26.8 \mathrm{~mm}$, and LVEF was $68.1 \%$. These data showed improvement of aortic valve regurgitation and cardiac function. He was discharged home on postoperative day 19 , and at a one-year follow-up, the patient was free of complications.

All procedures performed in this study were in accordance with the ethical standards of the institutional and/or national research committee(s) and with the Helsinki Declaration (as revised in 2013). Written informed consent was obtained from the patient for publication of this case report and accompanying images. A copy of the written consent is available for review by the editorial office of this journal.

\section{Discussion}

Although the treatment of stent grafts has been widespread 

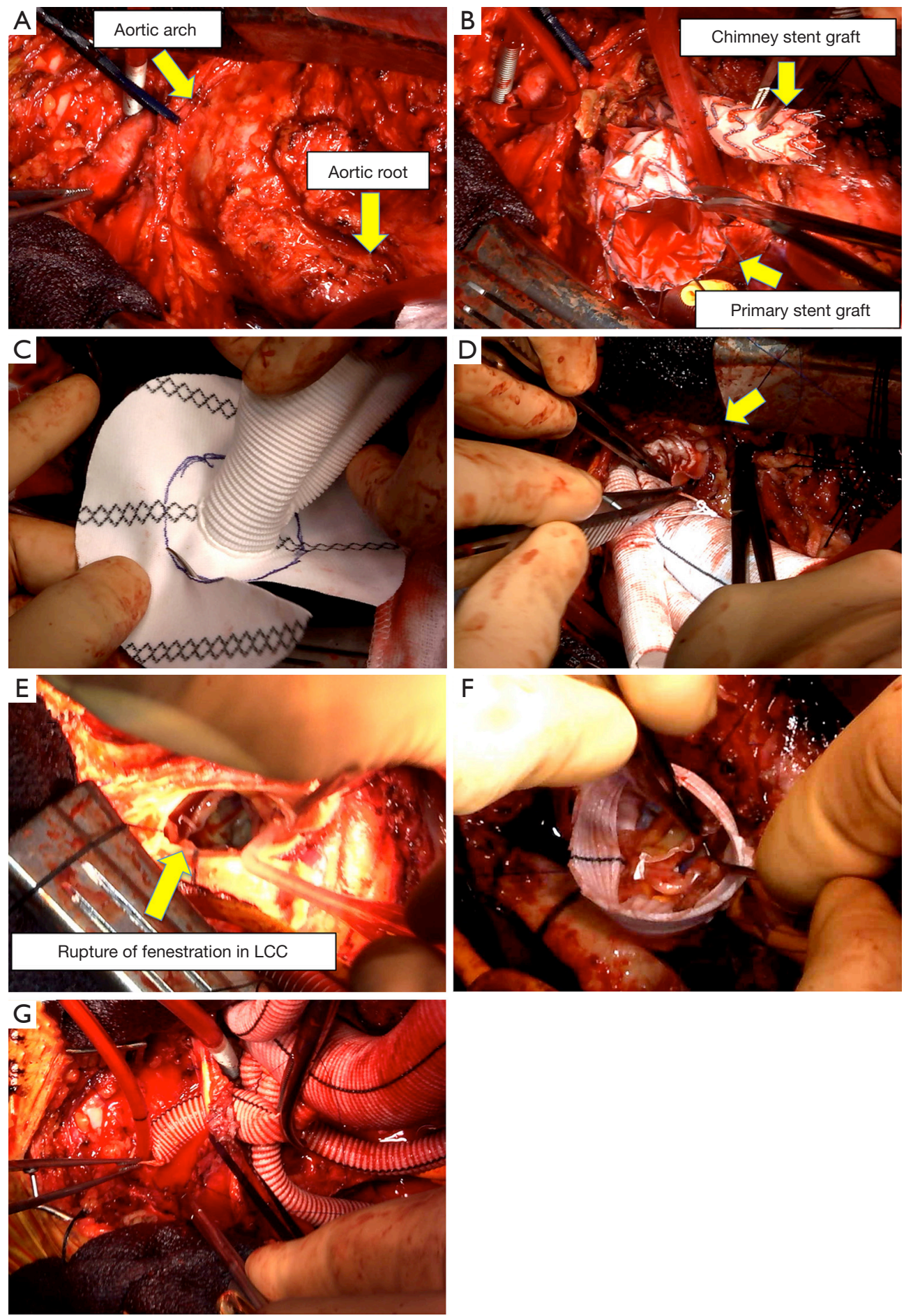

Figure 2 Operative findings. (A) Whole image from the aortic root to aortic arch. (B) The image of the chimney stent graft and primary stent graft. (C) The image of the trimmed collar of Vascutek Siena ${ }^{\mathrm{TM}}$ Collared Branched Graft. (D) The anastomosis image of the collar of the vascular prosthesis and the stent graft with the native aortic wall (arrow). (E) The appearance of the aortic root. (F) The image of reconstructed aortic root using reimplantation technique with and Gelweave ${ }^{\mathrm{TM}}$ Valsalva $26 \mathrm{~mm}$ and the left coronary cusp repaired with Gore-Tex sutures. (G) The image of reconstruction of the right carotid artery. LCC, left coronary cusp. 
A

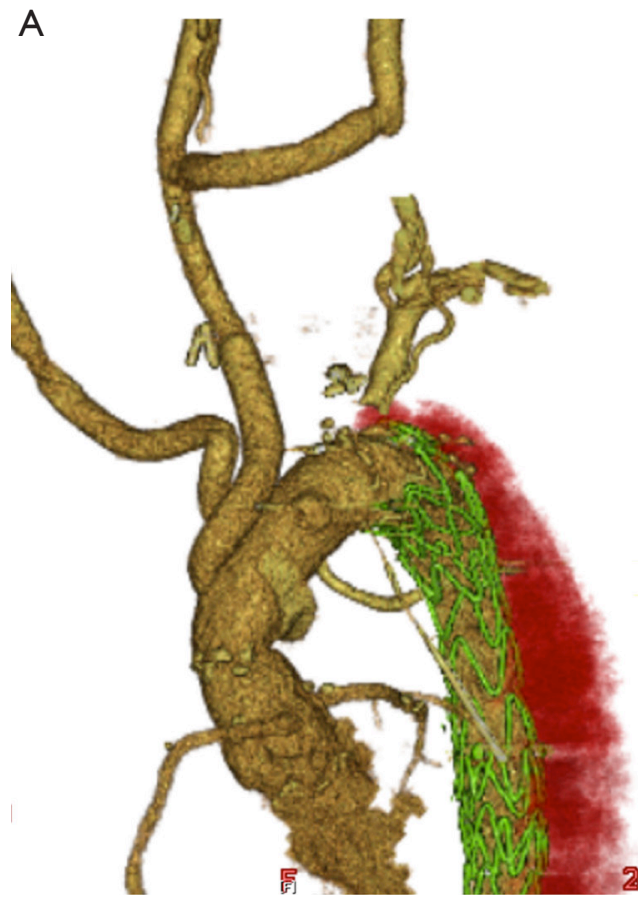

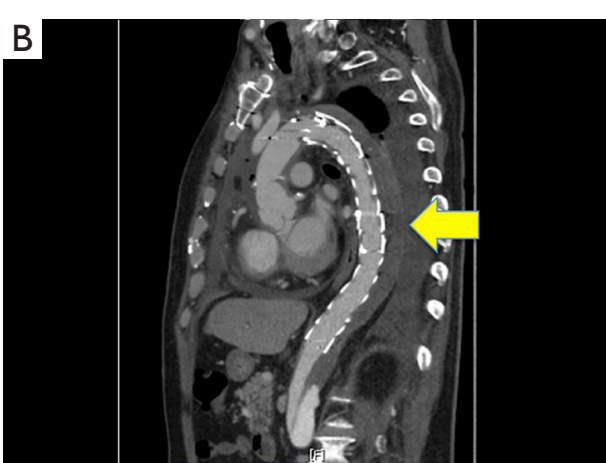

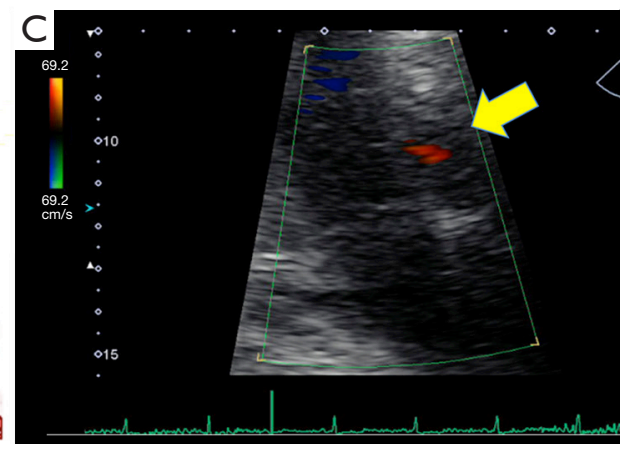

Figure 3 Postoperative finding (A) 3D-CT image. (B) Serial CT image with a thrombosed false lumen (arrow). (C) Ultrasonography image of decreased aortic valve regurgitation (arrow).

since the report of stent graft treatment in 1994, the spread has been limited to some extent because of the required secondary intervention in the remote period. Coselli et al. reviewed that in patients who have undergone TEVAR, the need for a secondary intervention is relatively common, with rates ranging from $10 \%$ to $15 \%$ when used for treating degenerative aneurysms, $16 \%$ to $24 \%$ when used for chronic type B aortic dissections, and $21 \%$ to $32 \%$ when used for acute type B dissections (8). In stent graft treatment of the aortic arch, branched stent graft, fenestrated stent graft, debranching, and chimney techniques have been used to overcome anatomical difficulties. As a result, the vasculature after TEVAR became different from native, so that more caution has been required in open conversion after that (9-11). In our case, previous open surgery for aortic dissection and multiple stent graft procedures led to an unusual situation so-called full metal jacket aorta. The expression of "full metal jacket aorta" is a term coined concerning the entirely stented coronary or peripheral artery by catheter intervention (12-14).

Points to keep in mind in this case are (I) securing a safe arterial cannulation site (II) eliminating the diameter difference between the stent graft and the artificial graft in anastomosis (III) the timing of root reconstruction.
First, in general, the ascending aorta, subclavian artery, and femoral artery are chosen for arterial cannulation site in establishing a cardiopulmonary bypass (15). Besides, aortic arch, descending thoracic aorta, abdominal aorta, and iliac artery are also available. In our case, it is difficult to use the ascending aorta as an arterial cannulation site because the stent graft was inserted from the arch aorta to STJ. Furthermore, it is dangerous to use only the femoral artery due to existing aortic dissection. Concerning the possibility of arterial cannulation to the left carotid artery, the risk of embolism was considered because there was a thrombus in the proximal side of the left carotid artery. Finally, we chose the bilateral axillary arteries and used the femoral artery additionally. In arterial cannulation to the axillary artery, we took a position of the patient with both hands open, exposing the axillary artery in the proximal side of the brachial artery (Figure 4). In this method, it is easy to approach the artery from the skin incision, but careful manipulations such as soft clamp and closing the arterial incision in one by one suture are required because of the arterial fragility.

Second, the selection of an artificial graft in the reconstruction by open repair after TEVAR is crucial, particularly in partial extraction or full salvage of the stent 


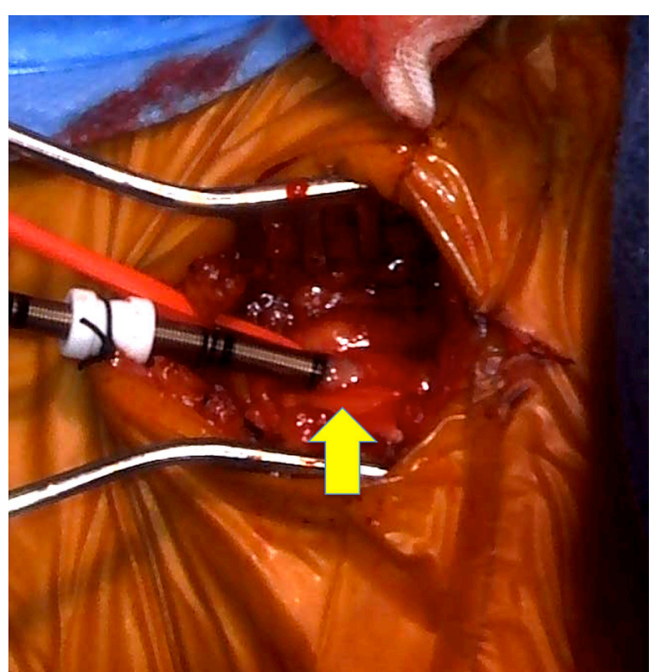

Figure 4 Image of arterial cannulation site to the axillary artery in the right arm (arrow).

graft. Although open repair after TEVAR can be classified as full extraction, partial extraction, or full salvage of the stent graft (8), our open repair was classified as partial extraction. When a large-diameter stent graft was inserted, it is sometimes difficult to select an artificial graft of an appropriate size. Jassar et al. reported a case using a Siena vascular prosthesis for aortic replacement after TEVARdiameter correction (16). We have chosen Vascutek Siena ${ }^{\mathrm{TM}}$ Collared Branched Graft for anastomosis to a large diameter stent graft stump, and have eliminated the diameter difference by anastomosing the collar of the vascular prosthesis and the stent graft with native aortic wall. This method is useful for open repair after TEVAR with a large-diameter stent graft.

Finally, we performed a valve-sparing aortic root replacement in the reconstruction of the aortic root. In operative findings, cause of aortic valve insufficiency was not only root dilatation but also rupture of fenestration in the left coronary cusp (Figure $2 E$ ). In the repair-oriented functional classification of aortic insufficiency, this case was classified as type Ib (17). Because this lesion may have already occurred in the acute dissection, aortic root repair in the first operation could have been considered. In an article by Beckmann et al. describing the results of this early repair, they reported that freedom from valve-related reoperation at 1,5 , and 10 years was $96 \%, 88 \%$, and $85 \%$, respectively (18). Similarly, Tanaka et al. reported that freedom from aortic valve reoperation was $83 \% \pm 9 \%$ at 5 years and $69 \% \pm 12 \%$ at 10 years (19). Given these favorable long-term outcomes, performing a self-valvesparing root reconstruction during initial surgery for aortic dissection may be an appropriate strategy.

\section{Conclusions}

We performed valve-sparing aortic root replacement in a case of aortic root dilatation with aortic valve regurgitation after Zone 0 chimney TEVAR. Because reoperation of post-TEVAR could be difficult due to unusual vascular structures, careful application of TEVAR for the aortic arch is required.

\section{Acknowledgments}

We greatly appreciate the support provided by the paramedical assistants of the operating room.

Funding: None.

\section{Footnote}

Provenance and Peer Review: This article was commissioned by the Guest Editors (Roberto Di Bartolomeo, Davide Pacini, Mohamad Bashir) for the series "Best Video Presentation Prize for the 10th Postgraduate Course on 'Surgery of the Thoracic Aorta' in Bologna" published in fournal of Visualized Surgery. The article has undergone external peer review.

Reporting Checklist: The authors have completed the CARE reporting checklist. Available at https://jovs.amegroups. com/article/view/10.21037/jovs-20-108/rc

Conflicts of Interest: All authors have completed the ICMJE uniform disclosure form (available at https://jovs. amegroups.com/article/view/10.21037/jovs-20-108/coif). The series "Best Video Presentation Prize for the 10th Postgraduate Course on 'Surgery of the Thoracic Aorta' in Bologna" was commissioned by the editorial office without any funding or sponsorship. The authors have no other conflicts of interest to declare.

Ethical Statement: The authors are accountable for all aspects of the work in ensuring that questions related to the accuracy or integrity of any part of the work are appropriately investigated and resolved. All procedures performed in this study were in accordance with the ethical standards of the institutional and/or national research 
committee(s) and with the Helsinki Declaration (as revised in 2013). Written informed consent was obtained from the patient for publication of this case report and accompanying images. A copy of the written consent is available for review by the editorial office of this journal.

Open Access Statement: This is an Open Access article distributed in accordance with the Creative Commons Attribution-NonCommercial-NoDerivs 4.0 International License (CC BY-NC-ND 4.0), which permits the noncommercial replication and distribution of the article with the strict proviso that no changes or edits are made and the original work is properly cited (including links to both the formal publication through the relevant DOI and the license). See: https://creativecommons.org/licenses/by-nc-nd/4.0/.

\section{References}

1. Dake MD, Miller DC, Semba CP, et al. Transluminal placement of endovascular stent-grafts for the treatment of descending thoracic aortic aneurysms. N Engl J Med 1994;331:1729-34.

2. Bavaria JE, Appoo JJ, Makaroun MS, et al. Endovascular stent grafting versus open surgical repair of descending thoracic aortic aneurysms in low-risk patients: a multicenter comparative trial. J Thorac Cardiovasc Surg 2007;133:369-77.

3. Desai ND, Burtch K, Moser W, et al. Long-term comparison of thoracic endovascular aortic repair (TEVAR) to open surgery for the treatment of thoracic aortic aneurysms. J Thorac Cardiovasc Surg 2012;144:6049; discussion 609-11.

4. Inoue K, Hosokawa H, Iwase T, et al. Aortic arch reconstruction by transluminally placed endovascular branched stent graft. Circulation 1999;100:II316-21.

5. Kawaguchi S, Yokoi Y, Shimazaki T, et al. Thoracic endovascular aneurysm repair in Japan: Experience with fenestrated stent grafts in the treatment of distal arch aneurysms. J Vasc Surg 2008;48:24S-9S; discussion 9S.

6. Andrási TB, Grossmann M, Zenker D, et al. Supra-aortic interventions for endovascular exclusion of the entire aortic arch. J Vasc Surg 2017;66:281-97.e2.

7. Ahmad W, Mylonas S, Majd P, et al. A current systematic evaluation and meta-analysis of chimney graft technology in aortic arch diseases. J Vasc Surg 2017;66:1602-10.e2.

8. Coselli JS, Spiliotopoulos K, Preventza O, et al. Open aortic surgery after thoracic endovascular aortic repair.
Gen Thorac Cardiovasc Surg 2016;64:441-9.

9. Roselli EE, Abdel-Halim M, Johnston DR, et al. Open aortic repair after prior thoracic endovascular aortic repair. Ann Thorac Surg 2014;97:750-6.

10. Davidovic L, Sladojevic M, Koncar I, et al. Late Complication after Thoracic Endovascular Aortic Repair: What Is the Role of an Open Surgical Conversion? Ann Vasc Surg 2018;47:238-46.

11. Joo HC, Kwon JH, Kim JH, et al. Late open conversion after thoracic endovascular aortic repair. J Vasc Surg 2019;70:439-48.e1.

12. Lee PH, Lee SW, Yun SC, et al. Full Metal Jacket With Drug-Eluting Stents for Coronary Chronic Total Occlusion. JACC Cardiovasc Interv 2017;10:1405-12.

13. Nguyen TC, Charitakis K. Wearing a full metal jacket should not be en vogue. J Thorac Cardiovasc Surg 2018;155:227-8.

14. Testi G, Ceccacci T, Cevolani M, et al. Substent Anchor Technique for Recanalisation of a Full Metal Jacket Femoropopliteal In-Stent Occlusion. EJVES Short Rep 2018;41:20-3.

15. Svensson LG, Blackstone EH, Rajeswaran J, et al. Does the arterial cannulation site for circulatory arrest influence stroke risk? Ann Thorac Surg 2004;78:1274-84; discussion 1284.

16. Jassar A, Kreibich M, Morlock J, et al. Aortic Replacement After TEVAR-Diameter Correction With Modified Use of the Siena Prosthesis. Ann Thorac Surg 2018;105:587-91.

17. Boodhwani M, de Kerchove L, Glineur D, et al. Repairoriented classification of aortic insufficiency: impact on surgical techniques and clinical outcomes. J Thorac Cardiovasc Surg 2009;137:286-94.

18. Beckmann E, Martens A, Pertz J, et al. Valve-sparing David I procedure in acute aortic type A dissection: a 20-year experience with more than 100 patients. Eur J Cardiothorac Surg 2017;52:319-24.

19. Tanaka H, Ikeno Y, Abe N, et al. Outcomes of valvesparing root replacement in acute Type A aortic dissection. Eur J Cardiothorac Surg 2018;53:1021-6.

doi: 10.21037/jovs-20-108

Cite this article as: Kawatou M, Minatoya K, Yamazaki K, Kanemitsu H, Sakamoto K, Sakai J. A case report of valvesparing aortic root replacement in a patient with full metal jacket aorta. J Vis Surg 2022;8:26. 